\title{
A Physiological Solvent for Crystalline Insulin
}

\author{
W. D. Lougheed, U. Fischer ${ }^{1}$, K. Perlman, and A. M. Albisser \\ The Hospital for Sick Children, Toronto, Canada, and ${ }^{\cdot}$ Zentralinstitut für Diabetes, Karlsburg, German Democratic Republic
}

Summary. Insulin is insoluble in water at physiological $\mathrm{pH}$, but dissolves relatively rapidly in plasma. To quantify the ability of various solutions to dissolve crystalline insulin, a simple assay measuring dissolution time was developed. At $\mathrm{pH} 7.5$ and room temperature, distilled water, $0.154 \mathrm{~mol} / 1 \mathrm{NaCl}$, Ringer's lactate solution, and $5 \%$ albumin in $0.154 \mathrm{~mol} / 1$ $\mathrm{NaCl}$ did not dissolve insulin crystals within $30 \mathrm{~min}$. Normal postprandial human plasma and a proteinfree cell culture medium dissolved insulin crystals within 3 to $8 \mathrm{~min}$. This ability was inhibited by acid titration of the fluids to a stable $\mathrm{pH}$ of 6.30 , at which point bicarbonate depletion could be implied. Repletion of bicarbonate did restore the ability of these solutions to dissolve insulin crystals, but back-titration to the initial $\mathrm{pH}$ with $\mathrm{NaOH}$ did not. The effect of sodium bicarbonate alone was strongly concentration dependent above $23 \mathrm{mmol} / \mathrm{l}$. We suggest that the ability of physiological fluids to dissolve insulin crystals at normal pH depends on their bicarbonate contënt. The ability to dissolve insulin with a physiological solvent which prevents its reaggregation promises to facilitate its use in portable pumping systems.

Key words: Insulin, crystal, dissolution, bicarbonate, $\mathrm{pH}$.

Aggregates of insulin occur under many conditions [1] and in this form have no biological effect [2]. We have recently reported that the addition of $1.5 \%$ $(\mathrm{v} / \mathrm{v})$ autologous serum markedly increased the biological activity of dilute insulin solutions [3]. Small quantitites of this substance prevented the aggregation of insulin which otherwise interfered with the flow of intravascularly pumped insulin and resulted in clinically unacceptable blood glucose control. To further explore this effect, we devised a simple in vitro assay to quantify the ability of various solutions to dissolve insulin crystals. The dissolution of crystalline insulin which does not occur in water at neutral $\mathrm{pH}$, is accelerated by increased hydrogen ion concentration ( $\mathrm{pH} \mathrm{2-3)}$. This process is used in the commercial preparation of insulin formulations which are subsequently back-titrated to physiological levels. However, solutions of this type have a tendency to reaggregate or precipitate. In this paper, we show that the bicarbonate ion greatly facilitates the dissolution of insulin crystals in the physiological $\mathrm{pH}$ range and that the ability of human plasma and other physiological solvents to dissolve insulin crystals is mainly determined by this ion.

\section{Methods}

Assay

Experimental equipment including a light microscope, a pH electrode, and a magnetic stirrer were placed in an Isolette infant incubator (Air Shields, Harboro, P. A., U.S.A.) at $24^{\circ}$ C. Sample aliquots of $5 \mathrm{ml}$ were dispensed into a $10 \mathrm{ml}$ beaker in the incubator and exposed when indicated to a humidified calibrated gas mixture of $\mathrm{CO}_{2}: \mathrm{O}_{2}: \mathrm{N}_{2}(5: 12: 83)$. Gas equilibration took approximately one hour during which time the sample was gently stirred and the $\mathrm{pH}$ was monitored ( $\mathrm{pH}$ meter PHM63 with a GK2421 electrode, Radiometer, Copenhagen, Denmark). A stable $\mathrm{pH}$ was indicative that $\mathrm{CO}_{2} / \mathrm{HCO}_{3}^{-}$equilibrium had been reached before the assay was commenced..

The dissolution time was measured as the elapsed time between the addition of a droplet of the test solution and the complete disappearance of a hexagonal insulin crystal viewed at $100 \times$ magnification. The initial step of the assay involved transferring pork insulin crystals (Connaught Laboratories, Toronto, Canada) to the grid of a clean Neubauer blood counting chamber. A single hexagonal crystal of 20-30 um diameter was then isolated using the tip of a 23 gauge needle. A $10 \mu \mathrm{l}$ aliquot of the test solution was finally pipetted onto the blood counting chamber (Micropipettor B, SMI Manufacturing Industries, Berkeley, Cal., U.S.A.) to form a small droplet covering the crystal.

\section{Samples}

Venous blood samples were drawn in heparinized syringes with no other additives from 7 healthy male and female subjects, aged 21 to 43 years. Immediately after sampling, the whole blood was centrifuged at $5000 \mathrm{~g}$ and $4^{\circ} \mathrm{C}$ for $15 \mathrm{~min}$. The plasma was then separated and stored at $4^{\circ} \mathrm{C}$ until it was assayed. In addition, samples of a protein-free cell culture medium (alpha-MEM) (4) distilled water, dilute $\mathrm{HCl}$ ( $\mathrm{pH} 3.0$ ), $0.154 \mathrm{~mol} / \mathrm{l} \mathrm{NaCl}$, Ringer's lactate solution, $5 \%$ human albumin in $0.154 \mathrm{~mol} / 1 \mathrm{NaCl}$, and solutions of 25 and $125 \mathrm{mmol} / 1 \mathrm{NaHCO}_{3}$ were studied.

\section{Protocol}

The initial dissolution tests for plasma and alpha-MEM were conducted in a $5 \% \mathrm{CO}_{2}$ environment. To remove bicarbonate from the sample, $\mathrm{HCl}(5 \mathrm{~mol} / \mathrm{l})$ was slowly added repeatedly to an aliquot which was kept in room air $\left(0.03 \% \mathrm{CO}_{2}\right)$ to establish and maintain a $\mathrm{pH}$ of $6.30-6.35$. During this time room air was blown over the surface of the stirred sample which was also intermittently 
Table 1. Dissolution time of insulin crystals in plasma from healthy subjects $(n=7)$ and in alpha-MEM (a protein-free cell culture medium, $\mathrm{n}=4$ ) as a function of bicarbonate ion concentration, $\mathrm{pH}$ and $\mathrm{pCO}_{2}$. Mean $\pm S E M$

\begin{tabular}{|c|c|c|c|c|c|}
\hline Sample + additive & $\begin{array}{l}\% \mathrm{CO}_{2} \text { in the } \\
\text { equilibrated } \\
\text { gas phase }\end{array}$ & $\begin{array}{l}\text { Initial } \\
\mathrm{pH}\end{array}$ & $\begin{array}{l}\mathrm{HCO}_{3}^{-} \\
\mathrm{mmol} / 1\end{array}$ & $\begin{array}{l}\text { Dissolution time } \\
\text { seconds }\end{array}$ & $\begin{array}{l}\text { t-test on } \\
\text { dissolution } \\
\text { time }\end{array}$ \\
\hline $\begin{array}{l}\text { 1. Plasma } \\
\text { 2. Plasma }+\mathrm{HCl} \\
\text { 3. Plasma } \pm \mathrm{HCl} \text { followed by } \mathrm{NaOH} \\
\text { 4. Plasma }+\mathrm{HCl} \text { followed by } \mathrm{NaHCO}_{3}\end{array}$ & $\begin{array}{l}5 \\
0.03 \\
0.03 \\
5\end{array}$ & $\begin{array}{l}7.52 \pm 0.01 \\
6.26 \pm 0.06 \\
7.52 \pm 0.01 \\
7.55 \pm 0.01^{b}\end{array}$ & $\begin{array}{l}22.9 \pm 1.4 \\
<5.0^{a} \\
<5.0^{2} \\
62.8 \pm 7.5\end{array}$ & $\begin{array}{l}441 \pm 44 \\
>1500^{c} \\
692 \pm 6^{c} \\
77 \pm 10\end{array}$ & $\begin{array}{l}\text { d } \\
\text { d }\end{array}$ \\
\hline $\begin{array}{l}\text { 1. Alpha-MEM } \\
\text { 2. Alpha-MEM }+\mathrm{HCl} \\
\text { 3. Alpha-MEM }+\mathrm{HCl} \text { followed by } \mathrm{NaOH} \\
\text { 4. Alpha-MEM + } \mathrm{HCl} \text { followed by } \mathrm{NaHCO}_{3}\end{array}$ & $\begin{array}{l}5 \\
0.03 \\
0.05 \\
5\end{array}$ & $\begin{array}{l}7.50 \pm 0.01 \\
6.34 \pm 0.01 \\
7.51 \pm 0.04 \\
7.51 \pm 0.03\end{array}$ & $\begin{array}{l}23.2 \pm 0.4 \\
<5.0^{\mathrm{a}} \\
<5.0^{\mathrm{a}} \\
19.5 \pm 0.2\end{array}$ & $\begin{array}{l}210 \pm 17 \\
>1800^{\mathrm{c}} \\
>1800^{\mathrm{c}} \\
193 \pm 19\end{array}$ & $\begin{array}{l}\bar{d} \\
\text { d } \\
\text { NS }\end{array}$ \\
\hline
\end{tabular}

a Concentration below the lower detection limit in all samples observed

b Due to slow equilibration with the gas phase, these $\mathrm{pH}$ values increased slightly during the assay

$c$ No indication of any crystal dissolution until time indicated in all samples observed

${ }^{d} p<0.01$ for the difference to assay No. 1

$\mathrm{NS}=$ denotes not significant for difference to assay No. 1

ultrasonicated (Ultrasonic Cleaner, Mettler Electronics Corp., Anaheim, Calif., U.S.A.) to accelerate the removal of $\mathrm{CO}_{2}$. Insulin crystal dissolution time was measured when $\mathrm{pH}$ was stable at this level. Sequential assays were performed in the same sample after back-titration to the initial $\mathrm{pH}$ first using $10 \mathrm{~mol} / \mathrm{l} \mathrm{NaOH}$ in room air and then using $1 \mathrm{~mol} / 1 \mathrm{NaHCO}_{3}$ in the $5 \% \mathrm{CO}_{2}$ atmosphere. All titrations were performed using a thin stainless steel wire for transferring minute aliquots of the electrolytes. The bicarbonate content in other aliquots of the samples was measured using the Coulter Electrolyte System '(Coulter Electronics, Hialea, Fla., U.S.A.) The individual dissolution times in plasma and alphaMEM were the means of triplicates. Statistical significance was evaluated using the Student's t-test. Results are presented as mean \pm SEM.

Insulin crystal dissolution times in the organic and inorganic solutions listed above were assayed in room air employing the same methodology. Except for the $\mathrm{NaHCO}_{3}$ and $\mathrm{HCl}$ solutions, the $\mathrm{pH}$ was adusted to 7.50 .

\section{Methodologic Observations}

The intra-assay coefficient of variation in the untreated plasma at a constant $\mathrm{pH}$ was $9 \%$ at low (mean $189 \mathrm{~s}$ ) and $13 \%$ at medium (mean $345 \mathrm{~s}$ ) dissolution times when the assay series was completed within $5 \mathrm{~h}$ of its start. Due to evaporation during the assay, the coefficient of variation could not be obtained for high $(>1500$ s) dissolution times. Sample storage for up to $12 \mathrm{~h}$ at $4{ }^{\circ} \mathrm{C}$ did not significantly influence dissolution time. However, haemolysis, freeze/thaw cycles, or simultaneous usage of several insulin crystals in one assay droplet led to inconsistent dissolution times and higher coefficients of variation. No protein precipitation occurred in plasma during acidification at $\mathrm{pH} 6.3$ but was evident below values of 6.1 . Aside from the results presented below, several assays were performed using pork insulin crystals from Nordisk Insulin Laboratorium (Copenhagen, Denmark) and several using serum instead of plasma. Dissolution times were unaffected by these conditions and no differences were observed between fasting and post-prandial plasma samples.

\section{Results}

In dilute $\mathrm{HCl}$ ( $\mathrm{pH} 3.0$ ), insulin crystal dissolution time was $242 \pm 19 \mathrm{~s}(\mathrm{n}=5)$. In distilled water $(\mathrm{n}=$
5), $0.154 \mathrm{~mol} / 1 \mathrm{NaCl}(\mathrm{n}=5)$, Ringer's lactate solution $(n=5)$, and $5 \%$ albumin $(n=5)$ insulin crystals did not dissolve during an observation time of $30 \mathrm{~min}$. In $25 \mathrm{mmol} / 1 \mathrm{NaHCO}_{3}$, the insulin crystals became fragmented in 2-3 min but dissolution was incomplete at $30 \mathrm{~min}(\mathbf{n}=20)$. However, in $125 \mathrm{mmol} / \mathrm{l} \mathrm{NaHCO}_{3}$, the insulin crystal dissolved within 40-50 s $(\mathrm{n}=10)$.

When equilibrated with a $\mathrm{pCO}_{2}$ corresponding to alveolar $\mathrm{pCO}_{2} 5 \%(\mathrm{v} / \mathrm{v})$, normal human plasma containing $22.9 \pm 1.4 \mathrm{mmol} / \mathrm{l}$ bicarbonate dissolved the insulin crystals in $441 \pm 44 \mathrm{~s}$ (Table 1 ). Insulin crystals did not dissolve in plasma at $\mathrm{pH}$ 6.26. Backtitration of these bicarbonate depleted samples to $\mathrm{pH}$ $7.52 \pm 0.01$ using $\mathrm{NaOH}$ did not restore the initial dissolution time. However, the use of $\mathrm{NaHCO}_{3}$ for back-titration to the initial $\mathrm{pH}$, led to a highly significant reduction in the dissolution time to $77 \pm$ $10 \mathrm{~s}$, with bicarbonate significantly elevated at 62.8 $\pm 7.5 \mathrm{mmol} / \mathrm{l}$.

In alpha-MEM the $\mathrm{pH}$ and $\mathrm{HCO}_{3}{ }^{-}$content with $5 \% \quad \mathrm{CO}_{2}$ equilibration were 7.28 and $17 \mathrm{mmol} / \mathrm{l}$ respectively. To obtain initial conditions comparable to the plasma specimen, the $\mathrm{pH}$ was adusted to 7.50 \pm 0.01 using $\mathrm{NaHCO}_{3}$. Dissolution time in these samples was $210 \pm 17 \mathrm{~s}$ when bicarbonate was 23.2 $\pm 0.4 \mathrm{mmol} / 1$. As with plasma, dissolution was inhibited by acidification to $\mathrm{pH} 6.34$ (Table 1). This inhibition persisted after back-titration with $\mathrm{NaOH}$ to the original $\mathrm{pH}$. The restoration of the bicarbonate content, however, was followed by complete recovery of the ability to dissolve insulin crystals.

\section{Discussion}

We have devised a simple in vitro method to assess and quantify the ability of aqueous solutions to dis- 
solve insulin crystals. Both the plasma of normal subjects and a protein-free but otherwise physiological solution dissolved the crystals at $\mathrm{pH}$ values which are normal for plasma [5].

The remarkable ability of these solutions to dissolve insulin was destroyed when bicarbonate was removed. It could not be restored by re-estabilishing the initial $\mathrm{pH}$ without restoring the bicarbonate content. The dissolution process was accelerated when the bicarbonate addition exceeded the initial concentration or if supraphysiological concentrations of $\mathrm{NaHCO}_{3}$ alone were investigated. Insignificant volumes of the electrolytes were added and the entire titration process could be repeated in the same sample with similar results.

In the absence of detectable bicarbonate levels at $\mathrm{pH} 7.52$ plasma and exhibited some dissolution of insulin which was not observed in the protein-free alpha-MEM. Both plasma and alpha-MEM contain mixtures of amino acids and the ability of these physiological solutions to dissolve insulin with only $23 \mathrm{mmol} / \mathrm{l}$ of bicarbonate exceeds that of bicarbonate alone. Thus it appears as if certain protein and/or amino acids enhance the effect of bicarbonate in dissolving insulin at physiological $\mathrm{pH}$. The mechanisms of these effects remain to be elucidated.

The unusual action of bicarbonate on insulin dissolution might explain various pathophysiological phenomena. In this regard, bicarbonate is reported to play an "essential" role in insulin secretion [6] and islet respiration [7]. Whether this role is connected to its action on insulin granules following exocytosis remains to be established. To exert a first pass effect on the liver natural insulin granules must rapidly dissolve to a certain extent in the blood following their secretion from the B-cells of the healthy pancreas [8]. In the absence of a supraphysiological perislet bicarbonate concentration, it-seems unlikely that physiologically secreted insulin granules dissolve completely during the few seconds it takes for them to reach the liver. It is tempting to speculate that pancreatic bicarbonate fulfills both an endocrine and an exocrine function. Furthermore, hepatic insulin extraction, which is reported to be $50 \%$ of the incoming insulin [9], may simply represent the removal of such partially dissolved granules. Previous observations in dogs support this hypothesis and indicate that $37 \%$ less insulin was required for glycaemic normalization when insulin was allowed ample time to dissolve in the presence of serum [3].

In the light of these observations the ability of plasma to dissolve insulin crystals may be altered in pathophysiological states with reduced bicarbonate concentrations such as metabolic acidosis. Accordingly, the well-known insulin resistance in diabetic ketoacidosis and its reversal by bicarbonate administration [10] may also be explained in part by changes in the ability of body fluids to dissolve insulin crystals.

The present need for stable, monomeric insulin solutions for insulin delivery devices may in part be satisfied by the addition of bicarbonate instead of serum to the insulin formulations. Unfortunately, bicarbonate containing solutions are difficult to stabilize with respect to $\mathrm{pH}$. In the meantime, further experimental and clinical studies involving intravascular insulin infusions can now proceed unhampered by the uncertainties of variable insulin dissolution.

Acknowledgements. This work was supported by negotiated contract NOl-AM-9-2201 from the National Institutes of Arthritis, Metabolism and Digestive Diseases of the National Institutes of Health, Bethesda, Maryland.

We are grateful to Dr. D. A. G. Mickle, Deputy Biochemist in Chief, Dept. of Clinical Biochemistry, Toronto General Hospital, Toronto, for the bicarbonate assays reported in this paper, to Drs. J. Clement and $H$. Martindale of Connaught Laboratories Ltd., Toronto, for the insulin crystals used in these assays, and to Mr. Bill Wiison and Ms. Ingrid Leitis, Dept. of Pathology, The Hospital for Sick Children, for laboratory assistance. Dr. U. Fischer was the recipient of an IREX Visiting Scientist Award during his stay at The Hospital for Sick Children in Toronto.

\section{References}

1. Lougheed WD, Woulfe-Flanagan $\mathrm{H}$, Albisser AM (1980) Insulin aggregation in artificial delivery systems. Diabetologia 19: $1-10$

2. Tantillo JJ, Karam JH, Burrill KC, Jones MA, Grodsky GM, Forsham PH (1974) Immunogenecity of "single peak" beefpore insulin in diabetic subjects. Diabetes 23: 276-281

3. Albisser AM, Lougheed W, Perlman K, Bahoric A (1980) Non-aggregating insulin solutions for long-term glucose control in experimental and human diabetes. Diabetes 29: 241-243

4. Stanners CP, Eliceiri GL, Green H (1971) Two types of ribosome in mouse hamster hybrid cells. Nature 230: 52

5. Altman PL, Dittner DS (1974) Biology data book, 2nd ed, vol III. Fed Am Soc Exp Biol, Bethesda Md, p 1947

6. Henquin JC, Lambert AE (1975) Extracellular bicarbonate ions and insulin secretion. Biochim Biophys Acta 381: $437-442$

7. Hutton JC, Malaisse WJ (1980) Dynamics of $O_{2}$ consumption in rat pancreatic islets. Diabetologia 18: $395-405$

8. Arquilla ER, Packer S, Tarmas W, Miyamoto S (1978) The effect of zinc on insulin metabolism. Endocrinology 103: $1440-1449$

9. Harding PE, Bloom G, Field JB (1975) Effect of infusion of insulin into portal vein on hepatic extraction of insulin in anesthetized dogs. Am J Physiol 228: 1580-1588

10. Cuthbert C, Alberti KGMM (1978) Acidemia and insulin resistance in the diabetic ketoacidotic rat. Metabolism [Suppl] 2: $1903-1916$

Received: April 28, 1980,

and in revised form: August 18, 1980

A. M. Albisser, Ph. D.

The Hospital for Sick Children

555 University Avenue

Toronto, Ontario M5G IX8

Canada 